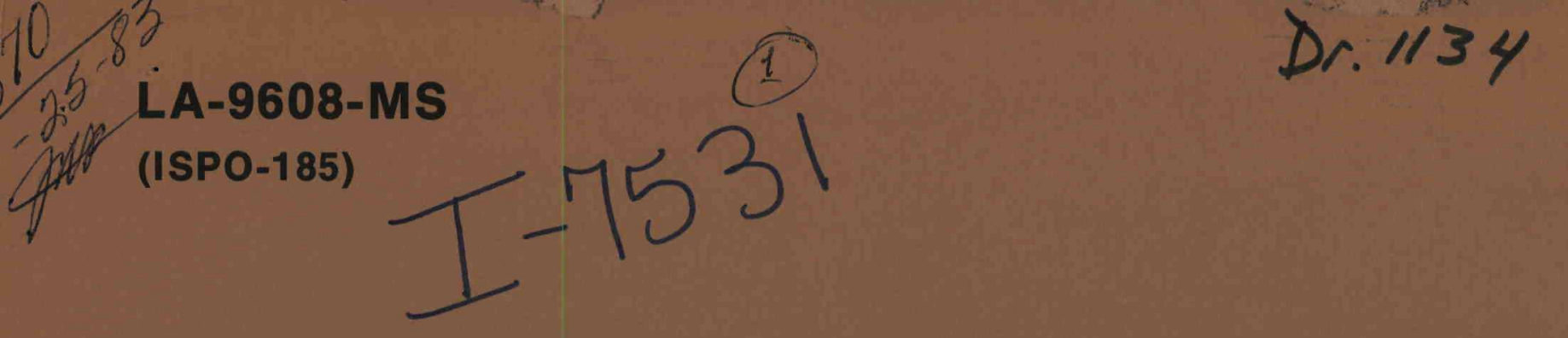

Los Alamos National Laboratory is operated by the University of California for the United States Department of Energy under contract W-7405-ENG-36.

PRCIGRAM FOR

USA

TECHNICAL ASSISTANCE

IAEA TO IAEA SAFEGUARDS

Department of Energy

Salegrards \& Security

\title{
Field Tests and Evaluations of the IAEA Active Well Coincidence Counter
}

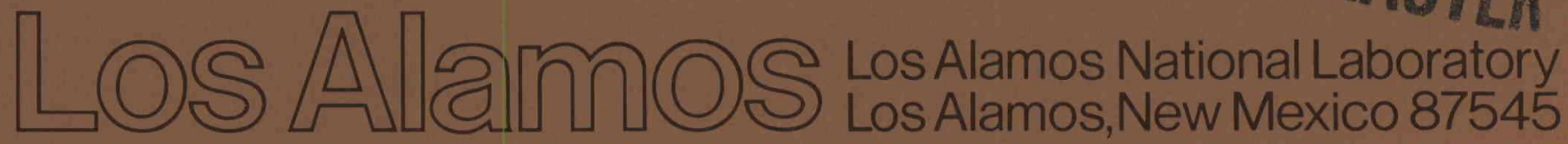


This work was supported by the US Department of Energy, Office of Safeguards and Security, and by the Program for Technical Assistance to IAEA Safeguards.

\section{Edited by Sarah Kreiner, Group Q-1}

Word processing and preparation by Jo Ann Barnes, Group Q-1

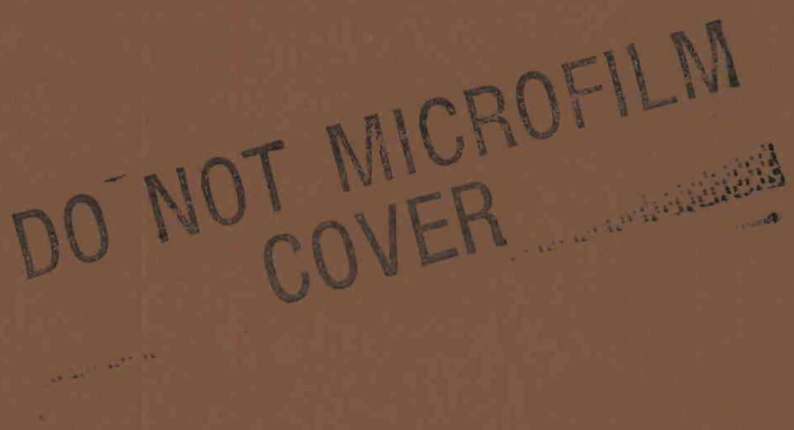

\section{DISCLAIMER}

This report was prepared as an account of work sponsored by an Agency of the United States Government. Neither the United States nor the United States Department of Energy, nor any of their employees, nor any of their contractors, subcontractors, or their employees, makes any warranty, express or implied, or assumes any legal liability or responsibility for the accuracy, completeness, or usefulness of any information, apparatus, product, or process disclosed, or represents that its use would not infringe privately owned rights. Further, neither the subject matter nor the content of this report reflects any policy, expressed or implied, by the United States Government. 


\section{DISCLAIMER}

This report was prepared as an account of work sponsored by an agency of the United States Government. Neither the United States Government nor any agency Thereof, nor any of their employees, makes any warranty, express or implied, or assumes any legal liability or responsibility for the accuracy, completeness, or usefulness of any information, apparatus, product, or process disclosed, or represents that its use would not infringe privately owned rights. Reference herein to any specific commercial product, process, or service by trade name, trademark, manufacturer, or otherwise does not necessarily constitute or imply its endorsement, recommendation, or favoring by the United States Government or any agency thereof. The views and opinions of authors expressed herein do not necessarily state or reflect those of the United States Government or any agency thereof. 


\section{DISCLAIMER}

Portions of this document may be illegible in electronic image products. Images are produced from the best available original document. 


\section{Field Tests and Evaluations of the IAEA Active-Well Coincidence Counter}

M. S. Krick

P. M. Rinard

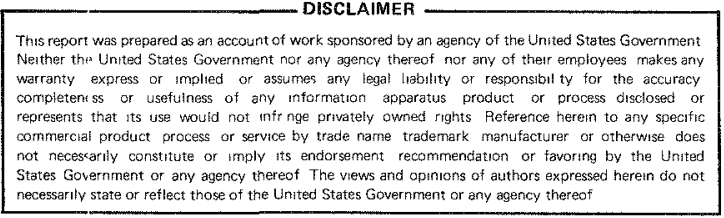


CONTENTS

ABSTRACT .......................... 1

I. INTRODUCTION ................ 1

II. FIELD TESTS AND EVALUATIONS ......... 3

A. MTR Fuel Assemblies .......... 3

B. High-Enrichment Uranium-0xide Powders . . . 6

C. Low-Enrichment Canned Materials ...... 10

D. Very Low Enrichment Materials ........ 11

III. MEASUREMENT PROCEDURES FOR TESTED MATERIALS.. .12

A. MTR Fuel Assemblies ......... 13

B. High-Enrichment Uranium-0xide Powders .... 13

C. Low-Enrichment Canned Materials ..... 14

D. Very Low Enrichment Materials ....... 14

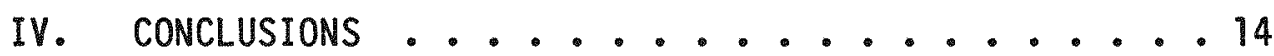

APPENDIX: CURVE FITTING BY DEMING'S METHOD.... .17

REFERENCES ................ 28 
FIELD TESTS AND EVALUATIONS OF THE IAEA ACTIVE WELL COINCIDENCE COUNTER

by

M. S. Krick and P. M. Rinard

\section{ABSTRACT}

This report summarizes and evaluates field tests of the Active Well Coincidence Counter (AWCC) at Winfrith and Dounreay, United Kingdom. The applicability of the AWCC for assaying the uranium content of a wide variety of materials was demonstrated and calibration curves were generated. The AWCC was used in three modes (fast, thermal, and passive) while assaying powders, pellets, cartridges, plates, assorted residues, and materials-testing-reactor fuel assemblies.

\section{INTRONUCTION}

The Active Well Coincidence Counter (AWCC) ${ }^{1}$ (Fig. 1) is designed primarily for assav of uranium fuel materials during field inspections and for quality control in a facility. The coincidence electronics unit counts events

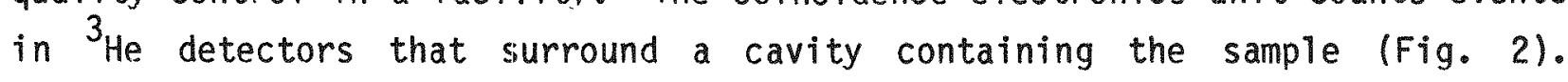
Fissioning in the sample is induced by neutrons from two AmLi sources. To achieve higher count rates, some of the moderators, absorbers, and reflectors in the AWCC can be used or removed, depending on the type of material being assayed. In this way, the AWCC can be used for bulk $\mathrm{UO}_{2}$ samples, highiy enriched uranium metals, light-water-reactor (LWR) fuel pellets, ${ }^{233}$-thorium fuel materials, alloys, dross, and wastes.

A secondary application, assay of ${ }^{238} U$ and plutonium samples, is available by removing the AmLi sources and operating the AWCC in its passive neutron coincidence mode. 


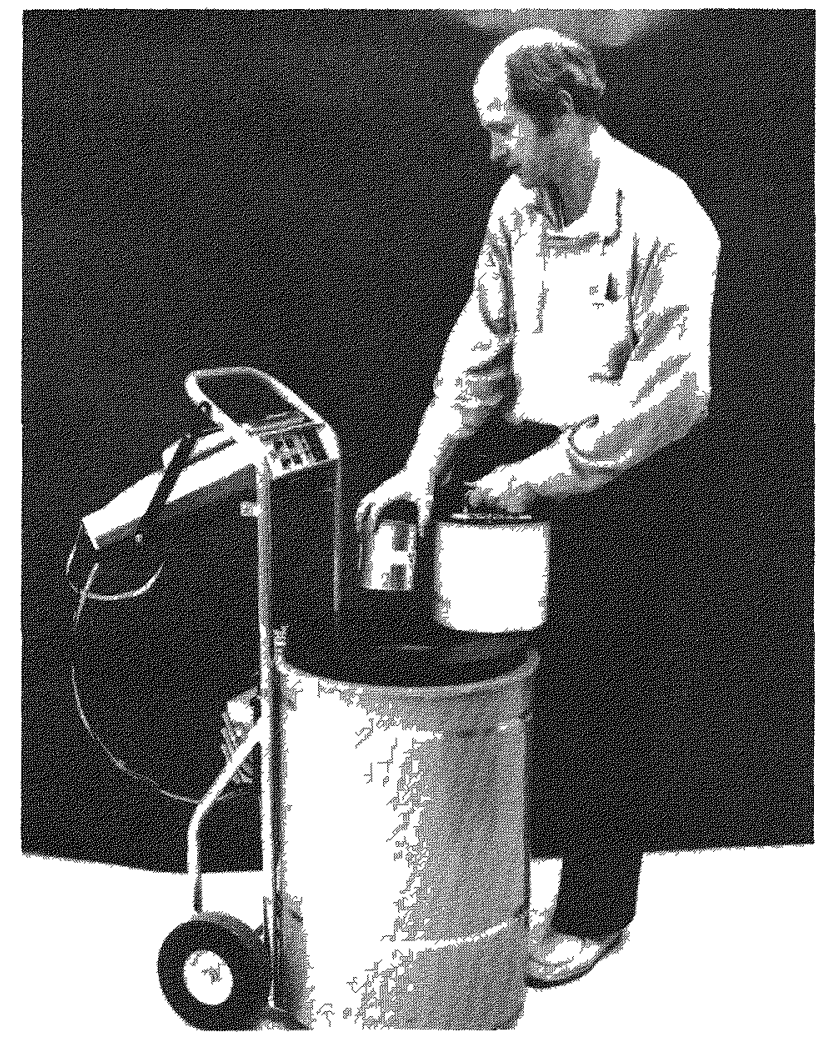

11g. 1. The AWCC consists of coincidence electronics and a ring of detectors surrounding the sample cavity. A sample can is shown being placed into the cavity: the end plug containing an AmLi source will then be replaced. A preamplifier box is mounted on the side of the cart. The electronics box mounted near the cart's handle provides the high voltage to the $3 \mathrm{He}$ detector tubes and also analyzes the detector pulses for coincidences.

Fig. 2. Top and side views of the inside of an AWCC are shown. Not indicated are removable sheets of cadmium that may be used to line the sample cavity.

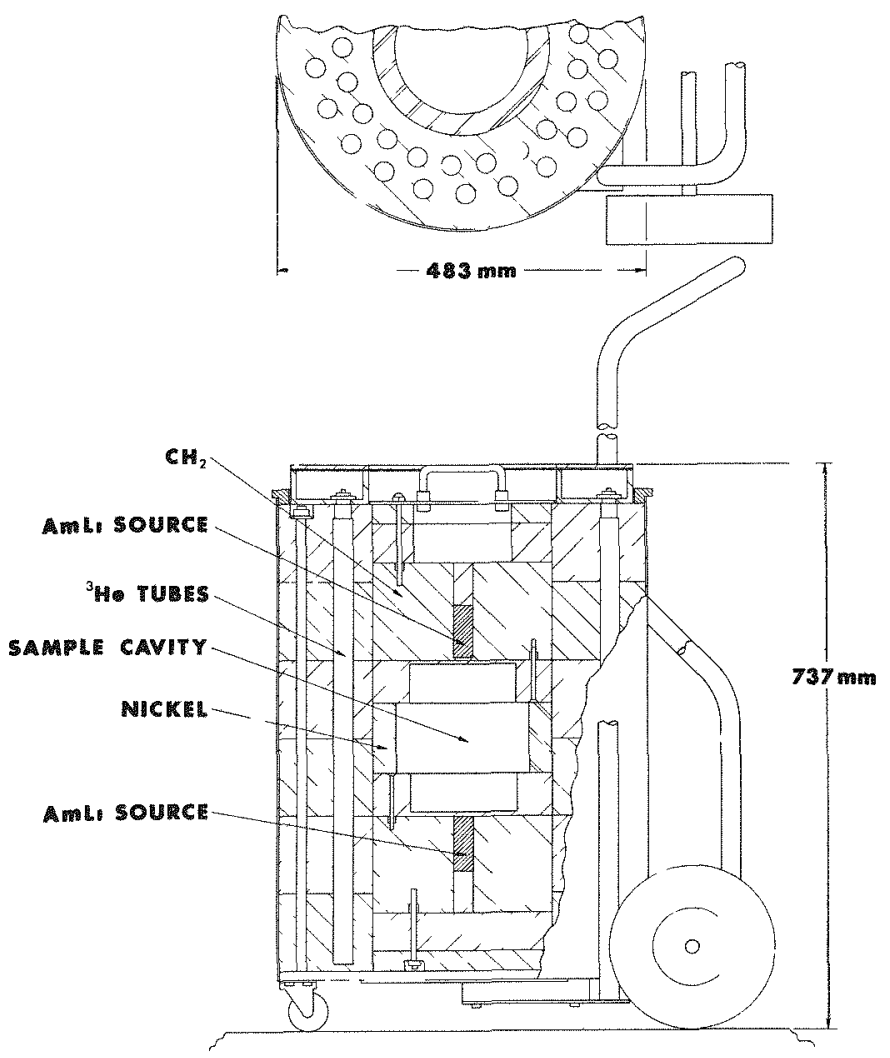


Materials that are too long to fit into the normal cavity may be assayed by removing the end plugs. Special inserts are placed inside the AWCC to hold the AmLi sources and such samples as fuel pins and assemblies.

Field tests of the AWCC have been conducted at Winfrith, United Kingdom (February 1982), and at the Dounreay Nuclear Power Station, United Kingdom (May 1982). This report discusses the wide variety of materials studied and the resuits of the tests.

\section{FIELD TESTS AND EVALUATIONS}

\section{A. MTR Fuel Assemblies}

At Dounreay, the AWCC was used with materials-testing-reactor (MTR) fuel assemblies. With the AWCC positioned horizontally and its end plugs removed, a cylindrical polyethylene insert was centered in the sample cavity (Figs. 3 and 4). A notch at the top of the cylinder allows insertion of an assembly, and a hole near the bottom is for a tube containing the AmLi sources (Fig. 5) that were previously in the end plugs.

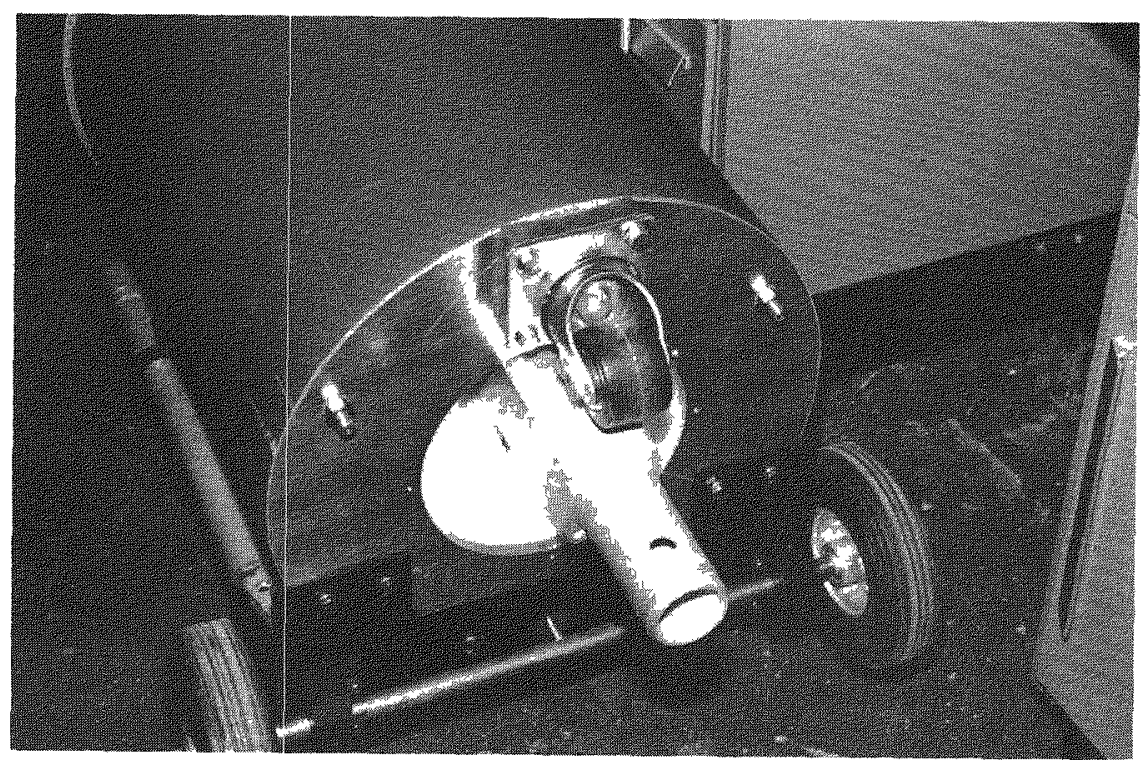

Fig. 3. The AWCC is shown on its side with the cylindrical polyethylene insert holding an MTR fuel assembly. When the AWCC is upright, the end shown is at the bottom. 


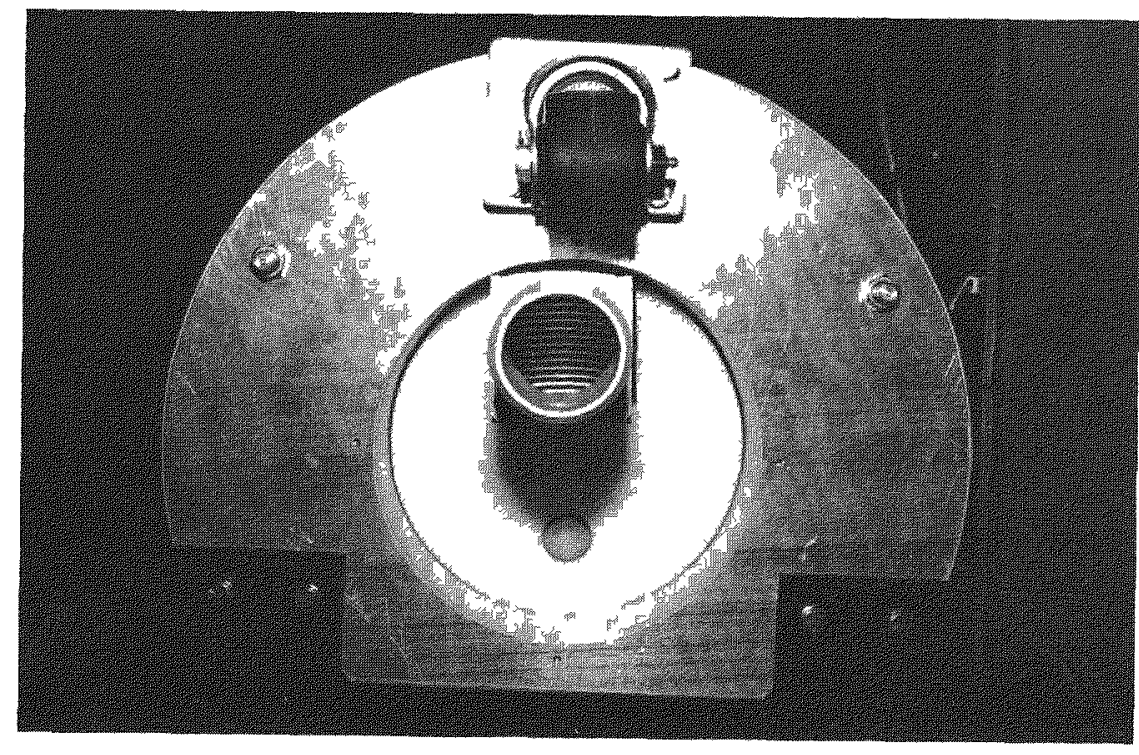

Fig. 4. Shown is a front view of the AWCC, polyethylene insert, and MTR fuel assembly. The curved plates of the assembly are shown in a horizontal orientation. The source tube is below the assembly near the bottom of the insert.

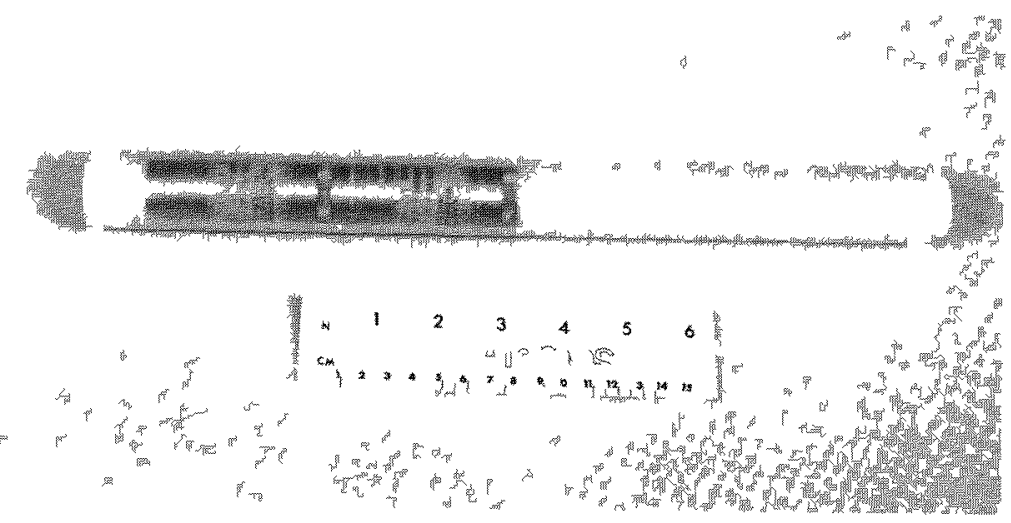

Fig. 5. Two AmLi sources are shown inside a polyethylene sleeve that fits into the insert illustrated in Figs. 3 and 4 . The geometries of the end caps on the sources are different, which allows the sources to fit into the sleeve with only one orientation. A polyethylene plug (shown on the right-hand side of the photograph) fills the sleeve. 
The MTR assemblies at Dounreay were centered in the insert's notch so that equal amounts of fuel extended from the ends of the AWCC. This technique provides a linear fuel density measurement (in grams per centimeter).

An assembly was measured with its 16 plates positioned first horizontally and then vertically, with no difference observed other than a difference in counting statistics. However, it is recommended that the plates be positioned vertically to provide the best opportunity for uniform irradiation of the fuel plates throughout the assembly.

With 16 flat plates and a holder, a mockup of an assembly was measured for $4,8,12$, and 16 vertical plates. A calibration curve for these data (Fig. 6) shows absorption effects, but not saturation. A normal assembly with 16 plates gave a response that was $4 \%$ greater than that from the 16 flat-plate mockup. Because the plates in the mockup assembly could not be placed as uniformly as with the normal assembly, geometry effects might have been responsible for the response difference.

The calibration curve of Fig. 6 has the shape fixed by the mockup measurements, but normalized to pass through the normal assembly's value. A power law and a parabola fit the data equally well. (The Appendix gives the details of the fitting procedure.) For $R=a m^{b}$, with $m$ in grams of ${ }^{235} U$ and $R$ in net coincidence counts per second, the parameters are $a=9.6 \pm 1.5$ and $b=$ $0.752 \pm 0.032$.

With $R=a m+b m^{2}, a=3.83 \pm 0.12$, and $b=-0.00705 \pm 0.00086$. With one plate removed, the coincidence rate is reduced by $3.5 \%$, which is 2.2 times the counting-statistics error of $1.6 \%(1 \sigma)$ found with a 4 -min measurement.

After a 4-min measurement, the counting-statistics error in the net totals counting rate (totals minus AmLi totals background) is only $0.3 \%$. As long as the geometry and background do not change, this high precision could be usefur for quality control during fabrication as well as for safeguards. But more experience is needed to determine if there are effects that can produce additional errors of this smal1 magnitude.

It has been demonstrated that the AWCC can be used as a practical instrument for verification of MTR fuel assemblies. With the use of simple procedures and standard electronics, a missing plate can be detected with more than 95\% confidence after a 4 -min coincidence response. If the net totals response can be used, the time required can be greatly shortened or the size of the smallest detectable missing mass can be reduced. 


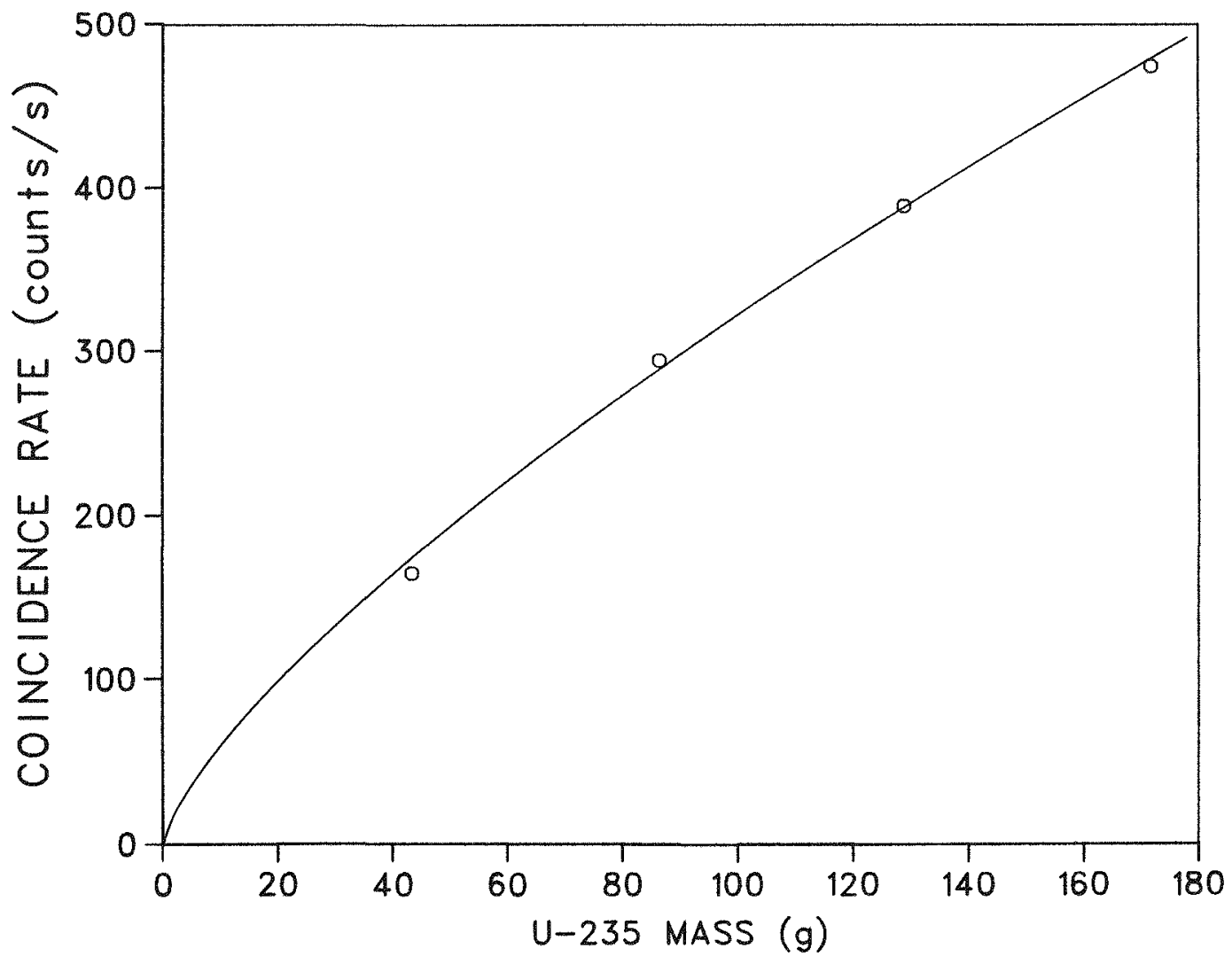

Fig. 6. The response curve of an MTR mockup as a function of number of plates shows some curvature due to absorption. Saturation does not occur when a full complement of 16 plates is used. The plates did not have equal masses, so the four data points shown are for the slightly irregular masses of $43.5,86.4,128.9$, and $171.8 \mathrm{~g}$. Counting-statistics errors are the same sizes as the circles indicating the data points. A fit to a power law gave this expression:

$$
R=(10.8 \pm 1.6) \mathrm{m}(0.737 \pm 0.030),
$$

where $m$ is the $235 \mathrm{U}$ mass in grams and $R$ is the response in net coincidence counts per second.

B. High-Enrichment Uranium-0xide Powders

Cans containing uranium-oxide powder were measured at Winfrith. The AWCC was used in its normal fast mode, which means that it was in an upright position with the AmLi sources in the end plugs and the nickel reflector and cadmium liner surrounding the cavity.

The cans were about 10 to $11.5 \mathrm{~cm}$ in diameter and from 12.5 to $19.5 \mathrm{~cm}$ high. Each can was always placed directly on the bottom end plug lat the 
bottom of the $20-\mathrm{cm}-h i g h$ cavity), even though this meant that a partially filled can would not have its powder centered in the cavity. The lack of symmetry was not important because the calibration curve should automatically contain the necessary asymmetry correction factor.

The Winfrith calibration curve was obtained for ${ }^{235} U$ masses from 53 to $698 \mathrm{~g}$ and enrichments from 9 to $93 \%$. One thousand seconds was the usuat counting time. The data (Fig. 7) indicate that a calibration curve may need to take into account the enrichment of the powder. Higher enrichment samples tend to produce lower count rates than do lower enrichment samples of similar masses. This observation has been substantiated by a multivariant analysis and function fit where the terms involving enrichment were statistically significant. $^{2}$ The recommended fit to these data is:

$$
R=0.120 E^{0.287} m^{(1.07-0.0646 \ln E),},
$$

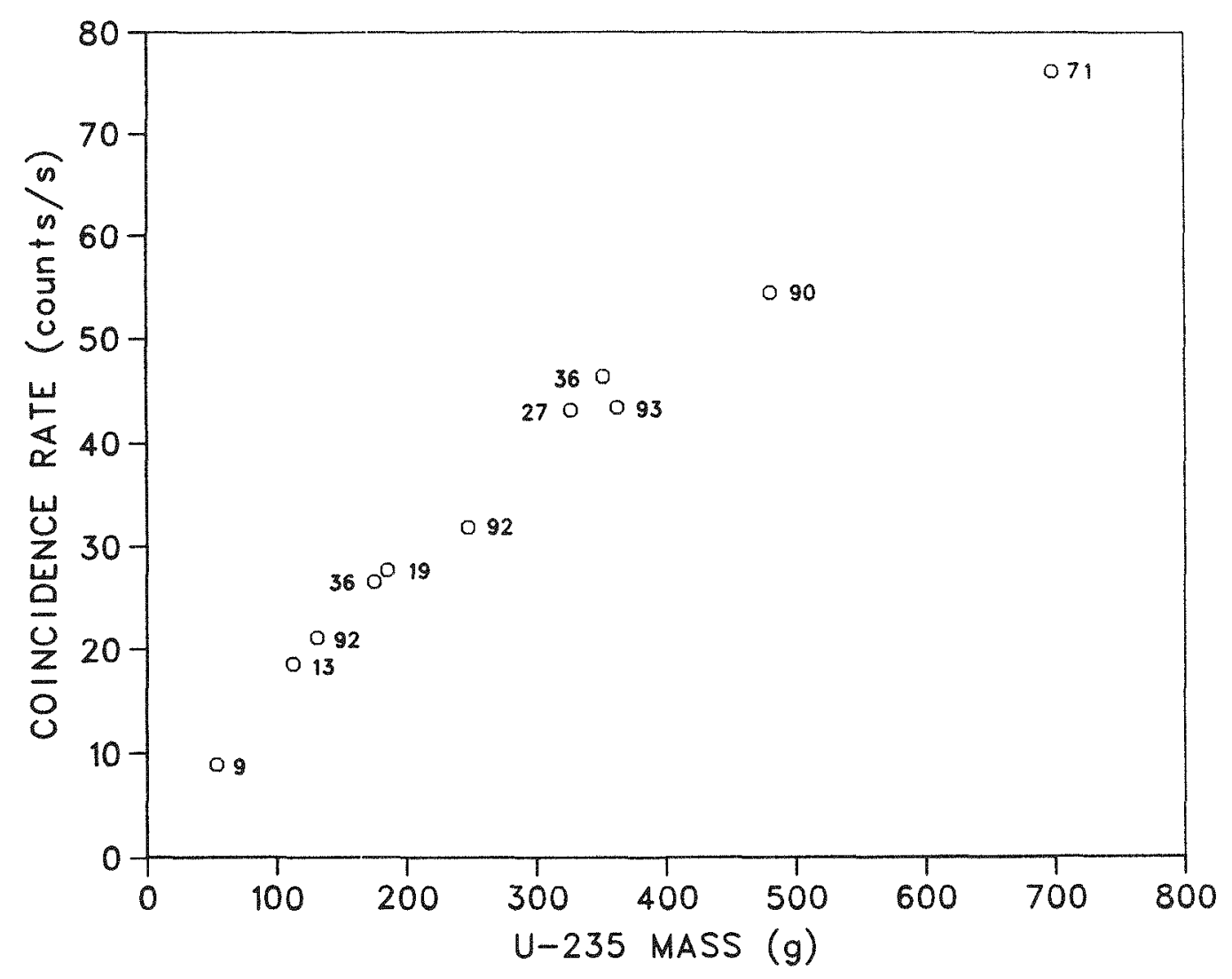

Fig. 7. Cans of high-enrichment uranium-oxide powders gave the normal fast mode responses shown here. The numbers beside the data points are the per cent enrichments. 
where $m$ is the ${ }^{235} U$ mass in grams, $E$ is the enrichment in per cent, and $R$ is the AWCC net coincidence response in counts per second. Representative plots of this function are shown in Fig. 8 .

Curves have also been fitted to three groups of samples, with all members of a group having similar enrichments: either nearly 15, 40, or 90\%. Except for the $90 \%$ enrichment data point at $120 \mathrm{~g}$, the data for a11 the members of each group can be fitted by a single curve (Fig. 9).

To investigate this enrichment dependence calculationally, a set of Monte Carlo simulations was performed using the Los Alamos National Laboratory MCNP code. ${ }^{3}$ The AWCC was modeled in detail; the 10-cm-diam samples, however, were centered in the cavity rather than placed on the bottom of the cavity. Three enrichments were used, matching those 1 isted in the previous paragraph. The results agree with those for the three groups of measured samples, including a

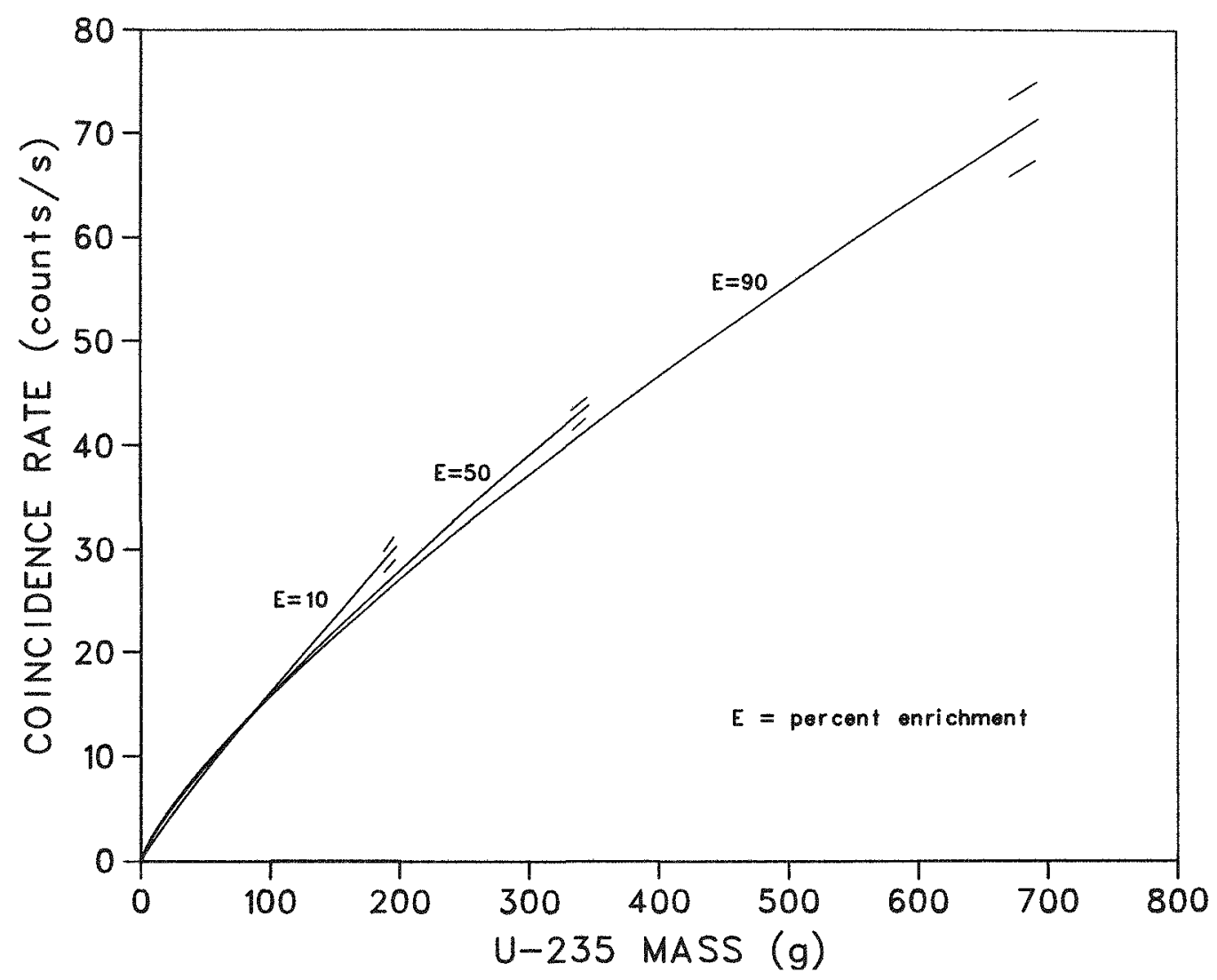

Fig. 8. The multivariant analysis with a power law fit gives these curves for three enrichments typical of the Winfrith samples. The short dashes at the end of each curve indicate the widths of the $95 \%$ confidence 1 imits at that mass value. These limits go to zero smoothly as the mass goes to zero. 


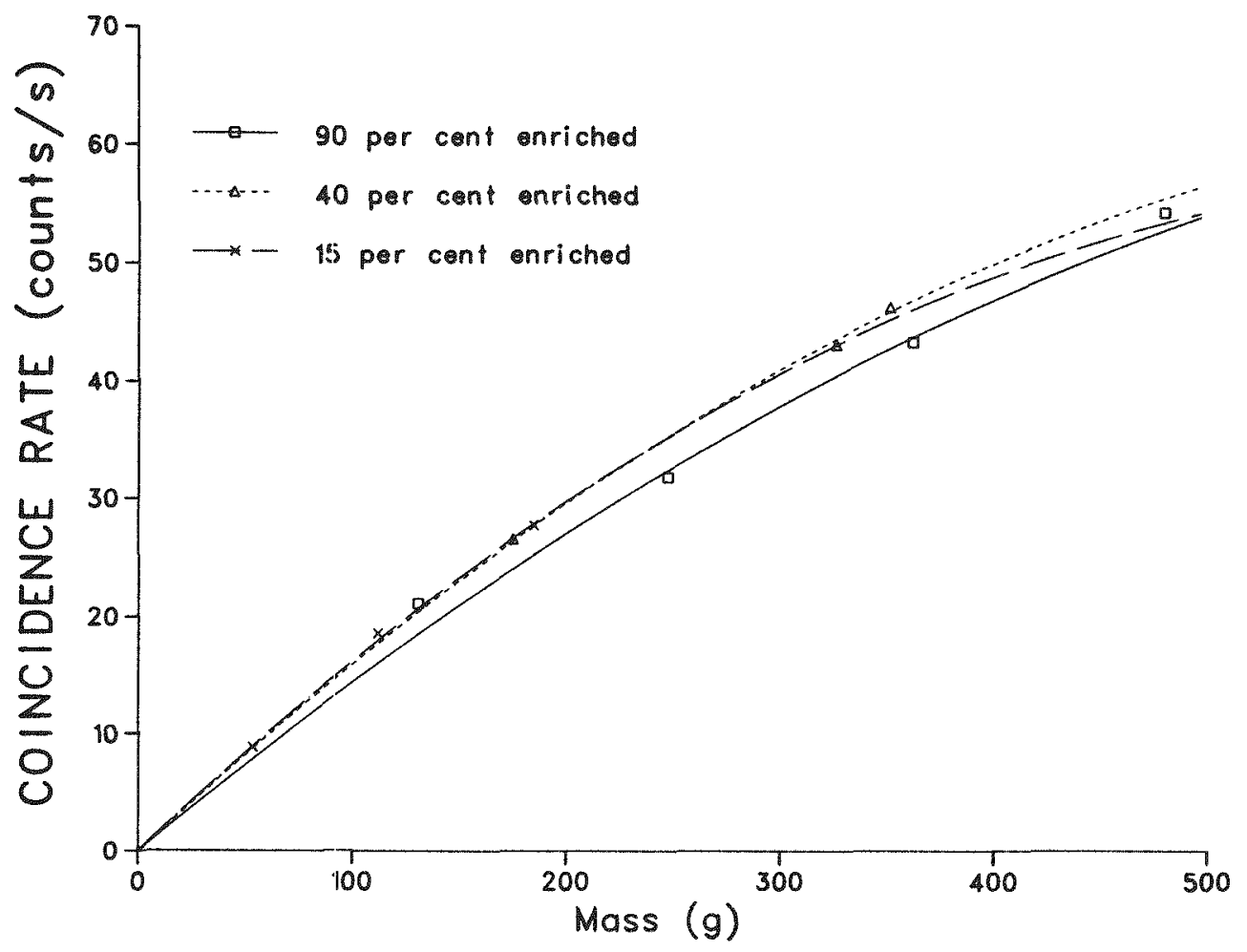

Fig. 9. The data in Fig. 7 have been separated into three groups according to enrichment. Representative values of the groups are $90 \%, 40 \%$, and $15 \%$ enrichment. Parabolic fits of the form $R=a m+b m^{2}$ were made for the three general regions of enrichments, where $R$ is the net coincidence response in counts per second and $m$ is the $235 \mathrm{U}$ mass in grams:

$$
\begin{array}{ll}
\text { near } 90 \% \text { enrichment, } & a=0.153 \pm 0.012 \text { and } \\
& b=-0.000087 \pm 0.000031 ; \\
\text { near } 40 \% \text { enrichment, } & a=0.1707 \pm 0.0073 \text { and } \\
& b=-0.000115 \pm 0.000022 ; \\
\text { near } 15 \% \text { enrichment, } & a=0.1750 \pm 0.0030 \text { and } \\
b=-0.000132 \pm 0.000029 .
\end{array}
$$

tendency of the $90 \%$ enrichment responses to rise less steeply for masses between 100 and $200 \mathrm{~g}$ than for masses below 100 or above $200 \mathrm{~g}$ (Fig. 10).

There appears to be a consistent deviation from the parabolic shape for masses between 75 and $250 \mathrm{~g}$, but the estimated errors on the calculated values are large enough to include the fitted curve for all the data points.

Using the AWCC on uranium-oxide powders with the highest accuracy thus requires additional information about the enrichment. The geometry of the sample is also an important factor. The cans measured were about $10 \mathrm{~cm}$ in diameter and thus large enough for multiplication to occur; they were always placed on the bottom of the cavity. 


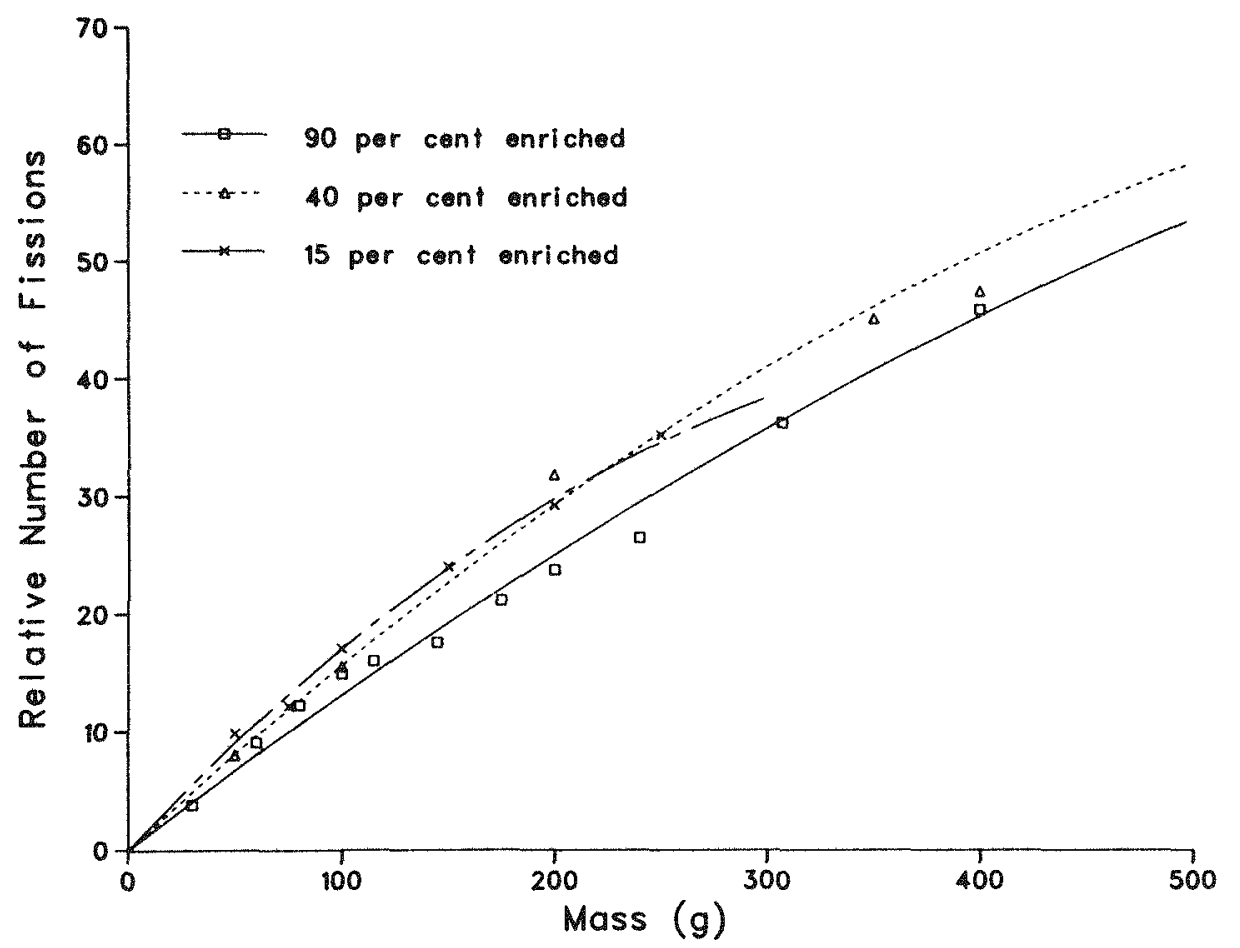

Fig. 10. Monte Carlo simulations of the measurements in Fig. 7 show the same features, in particular the enrichment dependence. The parabolic fits (see caption to Fig. 9) have these parameters:

$90 \%$ enrichment, $a=0.1363 \pm 0.0042, b=-0.0000589 \pm 0.0000075$

$40 \%$ enrichment, $a=0.1679 \pm 0.0078, b=-0.0001011 \pm 0.000019$;

$15 \%$ enrichment, $a=0.2029 \pm 0.0089, b=0.000258 \pm 0.000046$.

There appears to be a consistent deviation from the parabolic shape for masses between 75 and $250 \mathrm{~g}$, but the estimated errors on the calculated values are large enough to include the fitted curve for all the data points.

\section{Low-Enrichment Canned Materials}

Because self-shielding is not important for low-enrichment materials, the AWCC is used without the nickel reflector and the cadmium lining; this is its thermal mode. Smaller counting-statistics errors are a feature of this mode.

The cans of materials measured at Winfrith had various diameters and heights. When the height was greater than that of the cavity, the top end plug was simply placed on top of the can, rather than shortening both end plugs by removing some of their polyethyelene. The characteristics of the contents of the cans are shown in Fig. 11. Despite the diverse natures of the contents and the shapes of the cans, a single curve can be fitted to nearly all the data. (With a more uniform collection of sample types, a calibration curve could be 


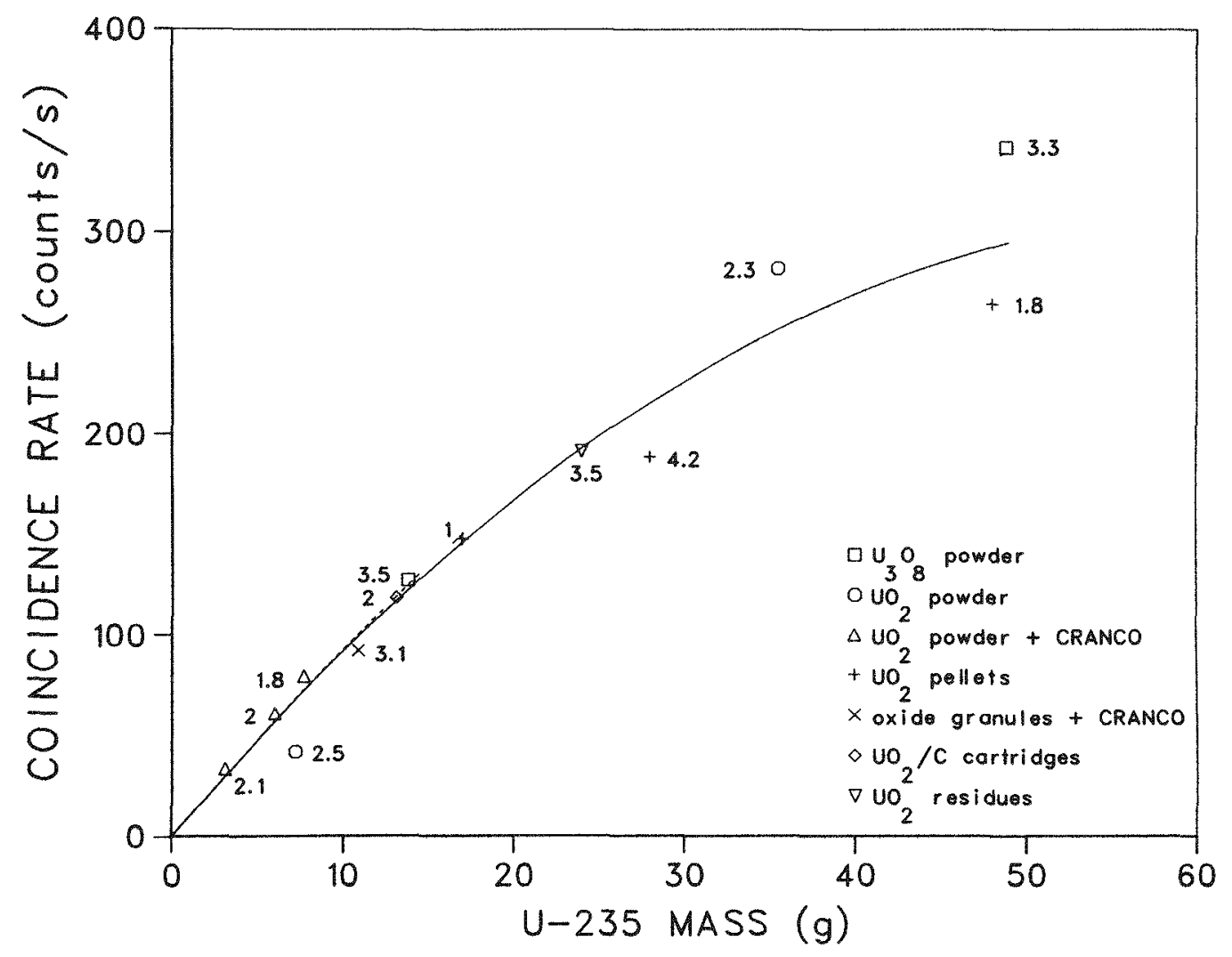

Fig. 11. Various low-enrichment materials in cans were measured using the thermal mode. The legend lists their forms, and the numbers by the data points give their per cent enrichments. With all the data used for a parabolic fit (see caption to Fig. 9), $a=9.98 \pm 0.69$ and $b=-0.081 \pm 0.017$ (solid line). Without the $\mathrm{UO}_{2}$ powder and pellets, $\mathrm{a}=9.87 \pm 0.26$ and $\mathrm{b}=$ $-0.0598 \pm 0.0069$ (dashed line).

created easily.) After a 100-s count, the statistical error for a 25-g sample was about $1.4 \mathrm{~g}$.

\section{Very Low Enrichment Materials}

Samples with enrichments from natural to $3.3 \%$ were measured at Winfrith using the thermal passive mode where the AmLi sources, the nickel reflector, and the cadmium sheets are removed. Large samples provide enough spontaneous fission neutrons from ${ }^{238} U$ for coincidence counting over a 1000-s count time. The ${ }^{235} U$ content can then be inferred from knowledge of the enrichment, or the enrichment can be deduced after a separate active measurement of the ${ }^{235} \mathrm{U}$ content. 
The various samples measured are indicated in Fig. 12. With self-shielding and multiplication not important, a straight line is a logical choice for a calibration curve, as is shown in the figure. For a $1000-\mathrm{s}$ count of a $4500 \mathrm{mg}$ sample of natural uranium, the counting-statistics error is equivalent to $120 \mathrm{~g}$ $238 \mathrm{u}$ or $1 \mathrm{~g}^{235} \mathrm{u}$.

\section{MEASUREMENT PROCEDURES FOR TESTED MATERIALS}

From the exercises at Dounreay and Winfrith, procedures can be recommended for measuring the types of materials encountered at these two facilities.

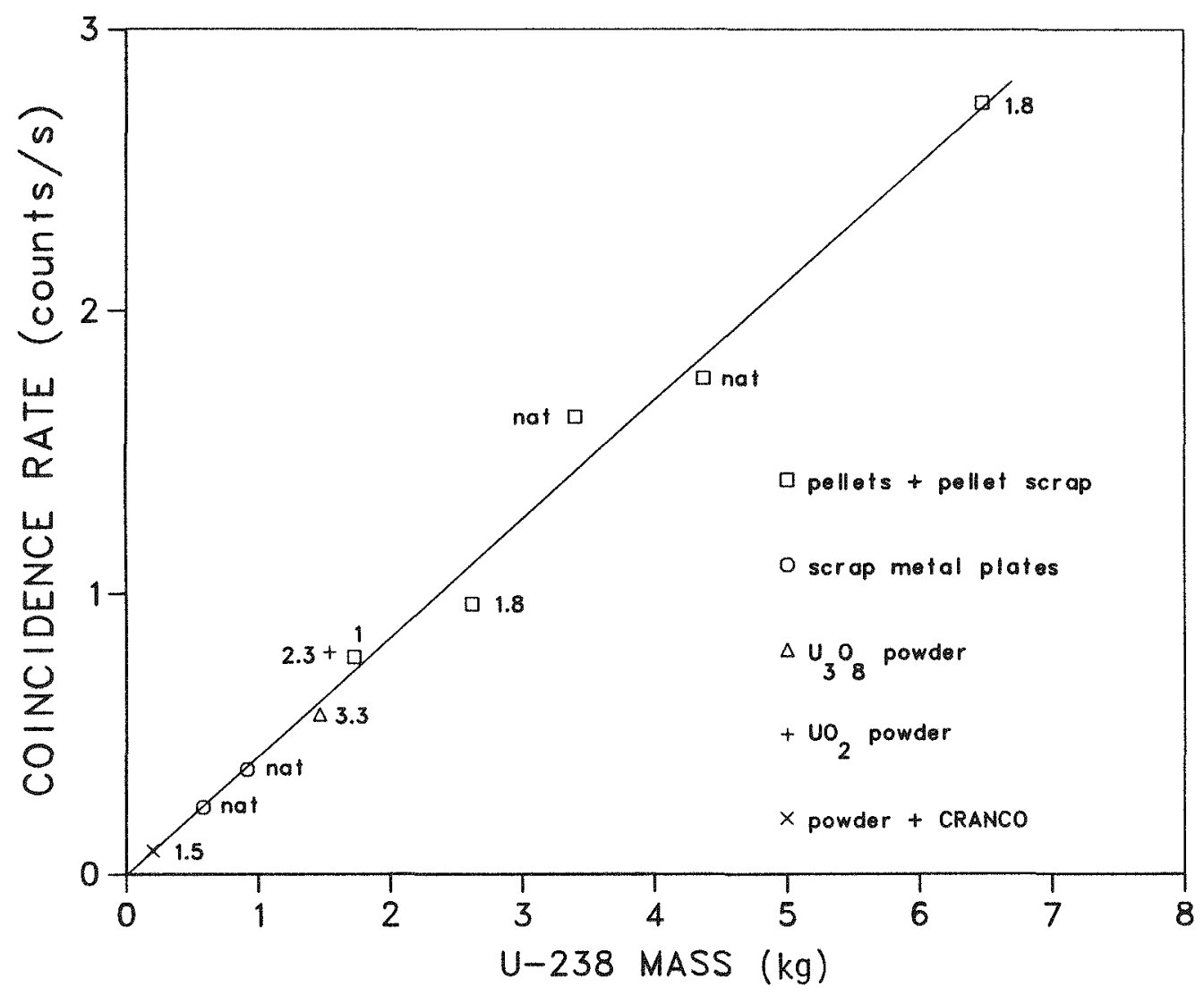

Fig. 12. The passive mode was used to measure the $238 \mathrm{U}$ content. The sample types are given in the legend and the numbers by the data points give their per cent enrichments (nat = natural). A straight-line fit through the origin gave a slope of 0.000419 \pm 0.000012 . 


\section{A. MTR Fuel Assemblies}

For MTR fuel assemblies, the AWCC is used in the horizontal rather than the vertical position. The end plugs, the nickel reflector, and the cadmium lining are removed.

A special insert is placed in the cavity to hold the assemblies and AmLi sources. This insert is a polyethylene cylinder with a notch at the top for the assemblies and a hole near the bottom for the sources. The insert should be centered in the cavity and precautions taken to ensure that it does not become displaced during insertion or removal of the assemblies.

With no fuel or sources present, a backgound check should give very nearly zero coincidence counts. Instrumental noise and nearby unknown sources can be detected by this check.

The sources are placed into a special holder that then slides into the hole of the polyethylene cylinder. The geometrical shapes of the sources guide the user into finding the proper orientation. A second background count rate is taken with the sources present so that net counts can later be calculated and a normalization constant can be provided for modification of a previously established calibration curve. Background counts should also be performed as part of the procedures for materials described in Secs. III.B, C, and D.

The MTR assemblies at Dounreay were centered in the insert's notch so that equal amounts of fuel extended from the ends of the AwCC. This technique provides a linear fuel density measurement (in grams per centimeter).

To assay the total fuel content of an assembly, two measurements should be made and their sum taken. The sources can be spaced apart to provide nearly uniform irradiations along the length of the insert. Then the assembly can be measured with one of its ends aligner with an end of the insert, followed by a second measurement with the other ends of the assembly and insert aligned. This two-position measurament was not attempted in the exercise discussed here. Even though the direction of the plates made no difference in these measurements at Dounreay, it is recommended that the plates be positioned vertically to provide the best opportunity for the most uniform irradiation of the fuel plates in the assembly.

\section{B. High-Enrichment Uranium-Oxide Powders}

For cans of high-enrichment uranium-oxide powders, the AwCC should be used in the normal fast mode with all the nickel and cadmium in place. With all 
cans placed directly on the bottom of the cavity, the material is not centered in the cavity; however, the calibration curve obtained at Winfrith includes the subsequent geometrical differences. All the cans studied were about the same diameter $(10$ to $11.5 \mathrm{~cm})$. (With much narrower cans, multiplication effects would be reduced and a new calibration required.)

A minor but statistically significant effect in working with these materials is the enrichment dependence of the calibration curve. An enrichment measurement (with a stabilized assay meter or multichannel analyzer) should be performed if a value is uncertain or needs verification.

\section{Low-Enrichment Canned Materials}

The thermal mode of the AWCC is the preferred mode for 1ow-enrichment materials because self-shielding is not significant and errors in counting statistics are smaller. The nickel reflector and the cadmium linings are therefore removed. The samples are placed on the bottom of the cavity in order to use the Winfrith calibration curve.

The experience with these materials at Winfrith shows that a single calibration curve can be used for a diverse collection of samples, but when possible it is preferable to develop a curve that is specific to a collection of samples with similar characteristics.

\section{Very Low Enrichment Materials}

When materials have enrichments below $23.5 \%$, the passive mode of the AWCC can determine the ${ }^{238} \mathrm{U}$ content, and then either (1) the declared enrichment allows the calculation of the ${ }^{235} \mathrm{U}$ amount, or (2) an AwCC active mode measurement of the ${ }^{235} \mathrm{U}$ amount (see Sec. II.C) can be used to check the declared enrichment.

In the passive mode, the AmLi sources are removed to a position where they do not affect the count rates. The Winfrith calibration curve was obtained with the nickel and cadmium inserts removed from the AWCC.

\section{CONCLUSIONS}

The field tests of the AWCC have demonstrated its applicability for assaying a variety of materials. Cans containing powders, pellets, cartridges, 
plates, and assorted residues were examined over an enrichment range up to $93 \%$. Three modes of AWCC operation were employed in the process: fast, thermal, and passive. MTR fuel was also examined, with the use of an insert to hold the assembly and to reposition the sources. It was shown that the response from a complete MTR assembly is not near a saturation value and that a missing plate from any position with the assembly is detectable with more than a 95\% probability in 4 min.

A calibration curve was determined for each mode of operation. For the passive mode, it was found that the best assay precision is obtained when the calibration is done over a narrow range of enrichments near the enrichment of the sample of interest. 
. 
The parameters of curves fitted to data in this report were obtained by a least-squares procedure developed by Deming. 4,5 The procedure allows for errors in both variables in a symmetric fashion, it can be used to fit any function to the data without the necessity of linearization, and it yields estimates of the true values of the coordinates near each data point.

Assume that an $i$ th data point has coordinates given by $X_{i}$ and $Y_{i}$. Errors in each coordinate are used to generate weighting factors $w_{x i}$ and $w_{y i}{ } A$ relationship between the two variables is assumed, usually in the form of $y=f(x)$. Estimates of the true values, $x_{i}$ and $y_{i}$, are to be found for each data point. These are also called calculated or estimated values of the variables. The function to be minimized is

$$
s=\sum_{i=1}^{n}\left[w_{x i}\left(x_{i}-x_{i}\right)^{2}+w_{y i}\left(y_{i}-y_{i}\right)^{2}\right]
$$

If $y_{i}=f\left(x_{i}\right)$ has $m$ parameters to be found and there are $n$ data points, then a total of $(n+m)$ parameters and calculated coordinates must be found. References 4 and 5 show the details. The codes to implement this technique are not particularly long or involved. The code that follows is written for the Hewlett-Packard HP-85 computer (with $32 \mathrm{k}$ of memory), so it is written in Hewlett-Packard's version of BASIC. With minor changes, and with the omission of the specialized video graphics section, it could be adapted to versions of BASIC for other microcomputers.

The user is led through the data input portion of the code upon execution. Note that initial estimates of the parameters in $f(x)$ must be given. To use the code with a computer that has additional memory, it is convenient to have simple curve-fitting routines automatically provide these estimates.

To change the fitting function, replace the contents within the parentheses of 1 ine 350, using $X 3$ for $X, Y 3$ for $y$, and $A 3(I)$ for the parameters. The correct number of parameters must be in line 340 . 


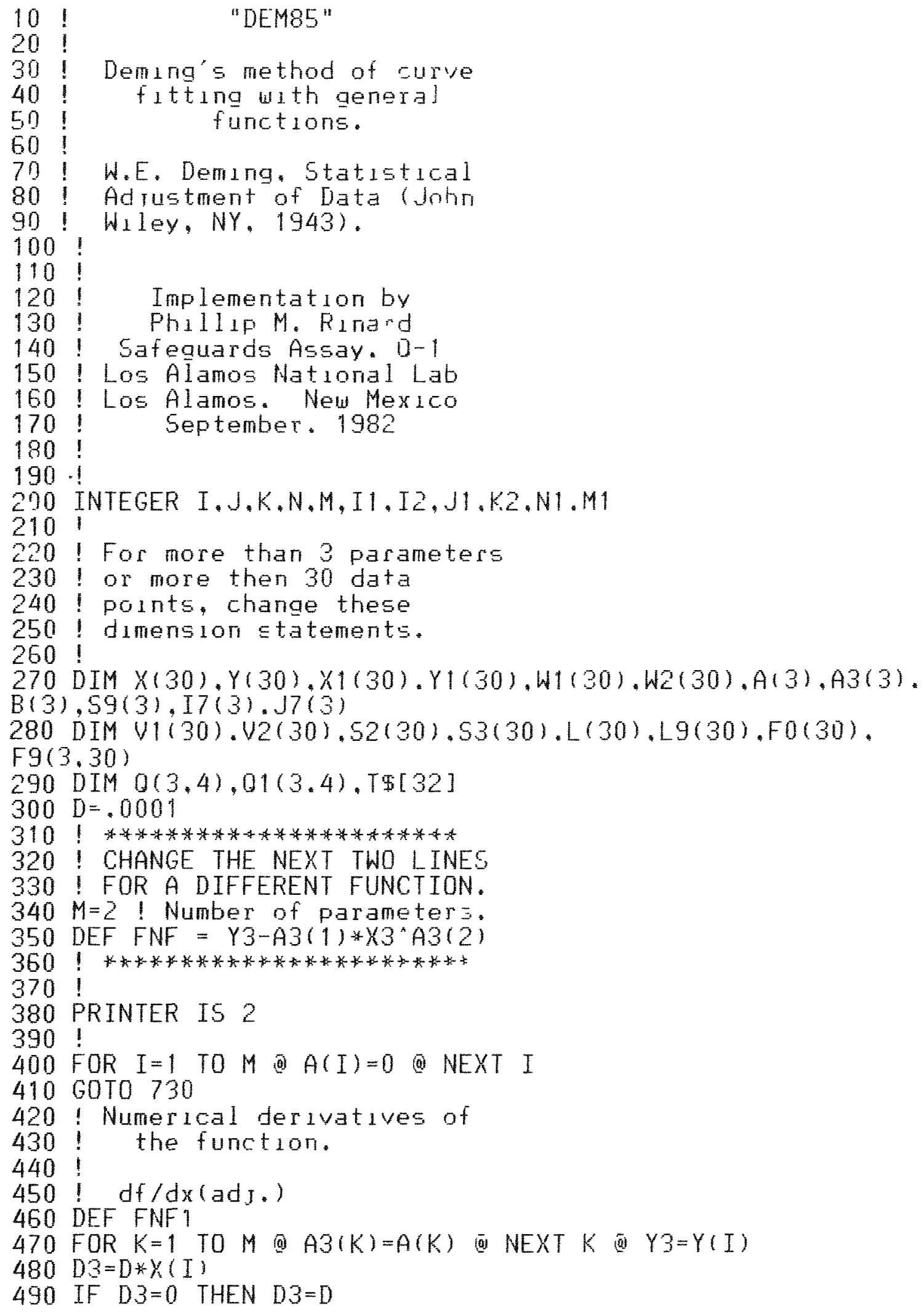


$500 \times 3=X(I) *(1+D / 2)$

510 IF $\times 3=0$ THEN $\times 3=0 / 2$

$520 \mathrm{~F} 1=\mathrm{FNF}$

$530 \times 3=X(I) *(1-D / 2)$

540 IF $\times 3=0$ THEN $\times 3=-(D / 2)$

$550 \mathrm{~F} 1=(\mathrm{F})-\mathrm{FNF}) / \mathrm{D} 3$

560 FNF $1=F 1$

$570 \mathrm{FN}$ END

580 END

590 I df/da( 1 )

600 DEF FNF 3

$610 \mathrm{FOR} K=1$ TO $M$ i $A 3(K)=A(K)$ NEXT $K$

$620 D 3=D+A(J)$

630 IF $\quad 03=0$ THEN $03=0$

$640 A 3(J)=A(J)+(1+D / 2)$

650 IF $A 3(J)=0$ THEN $A 3(J)=0 / 2$

660 F $3=F N F$

$670 A 3(J)=A(J)+(1-0 / 2)$

680 IF $A 3(J)=0$ THEN $A 3(1)=-(D / 2)$

$690 \mathrm{~F} 3=(\mathrm{F} 3-\mathrm{FNF}) / \mathrm{D} 3$

700 FNF $3=F 3$

$7: 0$ FN END

720 !

730 CLEAR

740 DISP "The desired fitting function"

750 DISP " must be in line 350,"

750 DISP " and the number of paramters"

770 DISF " must be in line 340."

780 DISP

790 DISP "For more than 30 data points"

800 DISP " or more than 3 parameters."

810 DISP " change Lnes 270-290."

820 DISP

830 DISP

840 PRINT "There are ":M:" parameters:"

850 PLIST 350.350

860 PRINT

870 DISP "Data entry is from..."

880 DISF " 1. keyboard"

890 DISP " 2. Tape File"

900 DISP

910 INPUT I

920 ON I GOTO 950.1540

930 CLEAR

940 DISP "What type of data?"

950 DISP " 1. Errors $1 \pi x \& y . "$

960 DISP " 2. Errors $1 \pi$ y only."

970 DISP " 3. Errors $1 \pi$ y only."

980 DISP " 4. No errors in $x z y . "$

990 INPUT II 


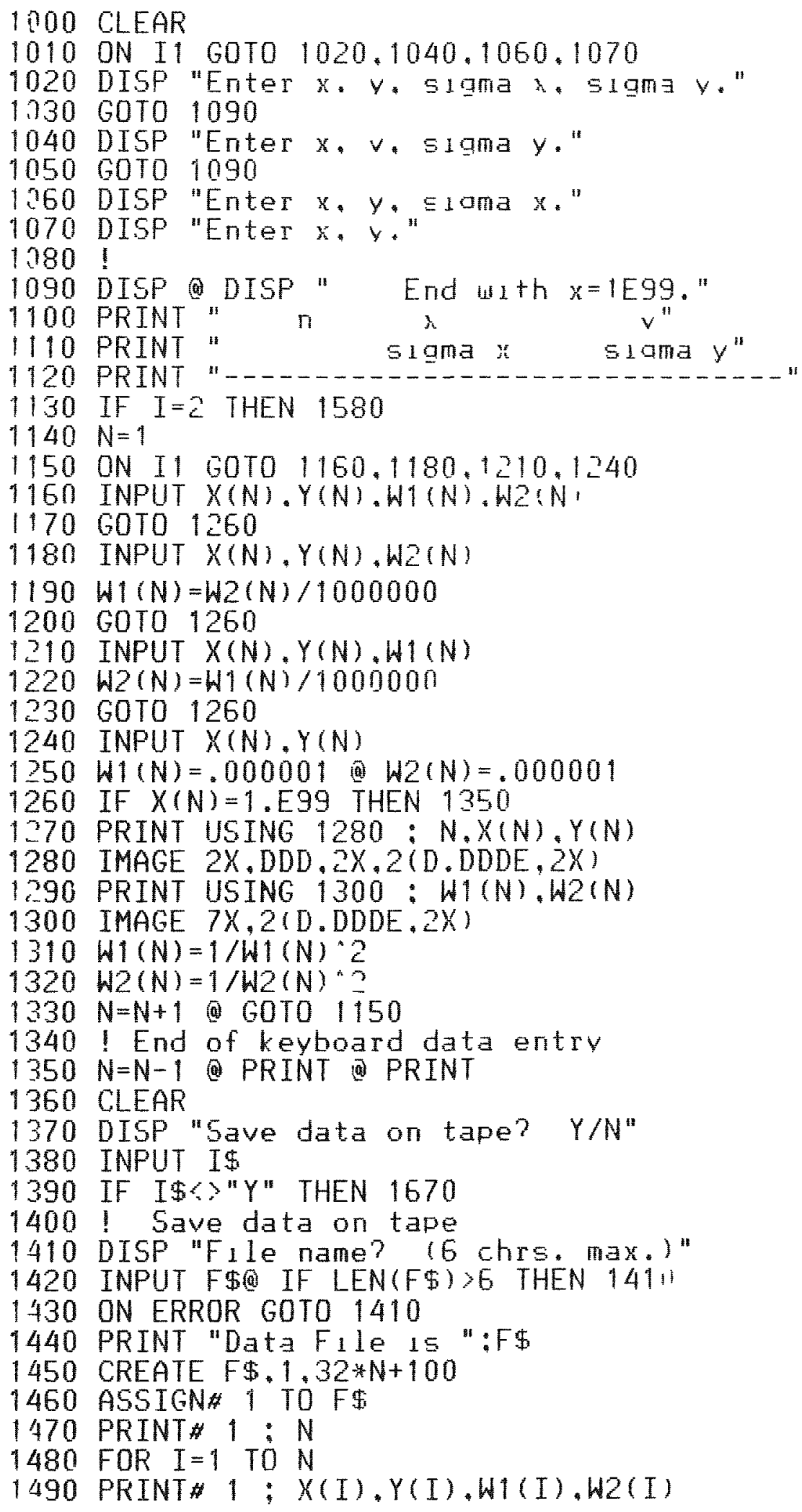




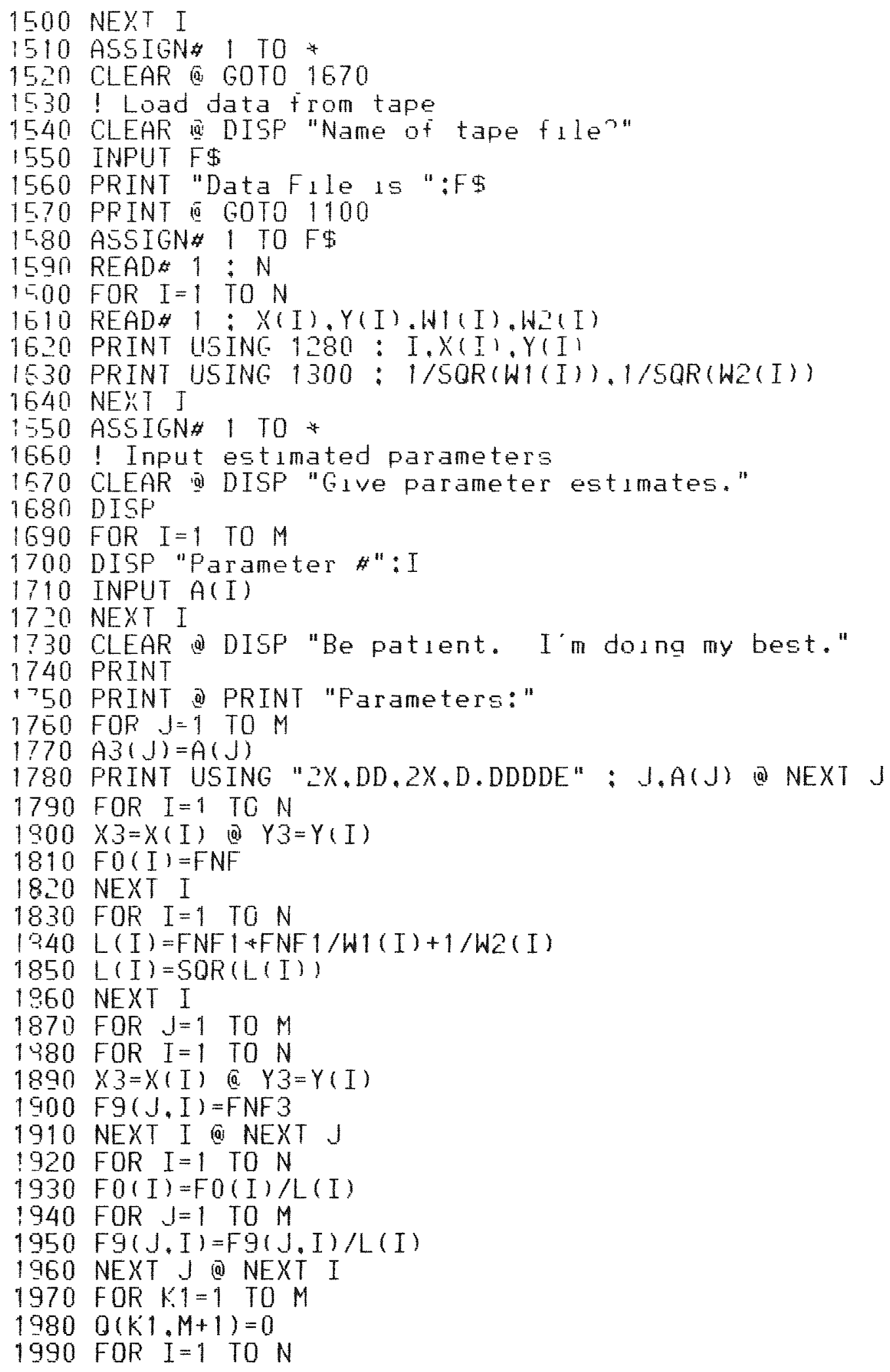




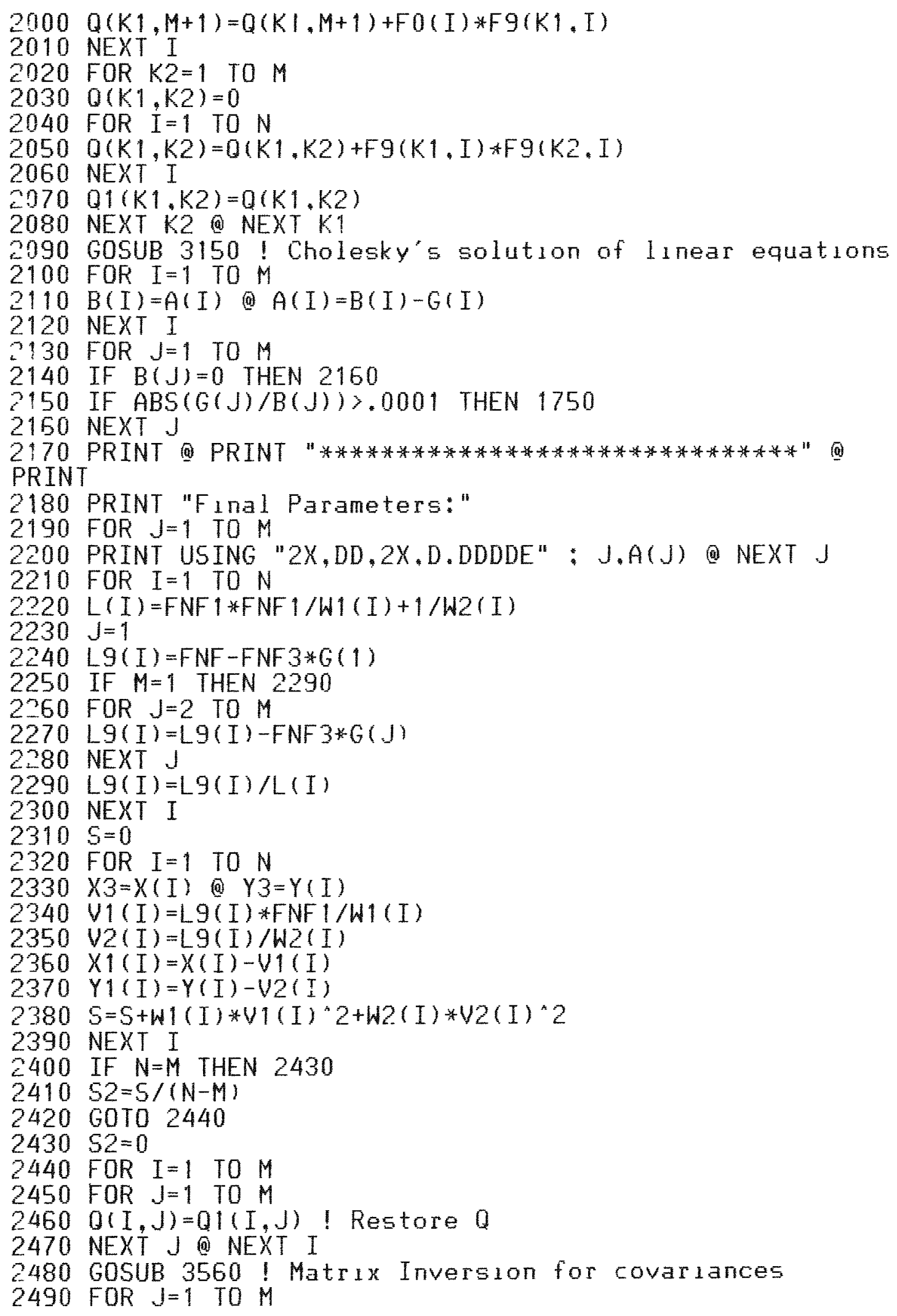


$250059(J)=\operatorname{SOR}(0(\mathrm{~J}, J) * 52)$

2510 NEXT J

2520 PRINT "Std. Errors in Parameters:"

2530 FOR $J=1$ TO $M$

2540 PRINT USING "2X.DD.2X.D.DDDE" : J.S9(J)@NEXT J

$2550 \quad$

$2560 !$ t-Table for $95 \%$ conf idence

2570 DATA $12.706 .4 .303,3.182 .2 .776,2.571 .2 .447,2.365$

2580 DATA $2.306,2.262 .2 .228,2.201,2.179,2.16,2.145,2.131,2$.

2.012 .2 .11

2590 DHTA $2.101,2.093,2.086 .2 .08,2.074,2.069 .2 .064,2.06$.

$55,2.052$

.500 DATA 2.048 .2 .045 .2 .042 .1 .96

$2610 T=1.67$ RESTORE 2570

2920 IF $N-2>30$ THEN 2640

2630 FOR $I=1$ TO $N-2$ GEAD T@ NEXT I

2540 PRINT 0 PRINT "Varıances and Covarıances:"

2650 FOR $K=1$ TO M G FOR $L=k$ TO $M$

2660 PRTNT USING $2670: K, L, S 2 * Q(K, L)$

2670 IMAGE $2 X, D D, 2 X, D D, 3 X, D . D D D E$

7.80 NEXT $L$ j NEXT $K$

$2690 \%$ Std. Errors $1 \pi y$

2700 FOR II $=1$ TO $\mathrm{N}$

$2710 \times 3=X(I 1) @ Y 3=Y(I I)$ (0) $53($ II) $=0$

2720 FOR $J 5=1$ TO $M$

$2730 \quad J=J 5$ O $F 4=F N F 3$

$274053($ II $)=53($ II $)+0(J 5, J 5) * F 4 * F 4$

2750 IF $M=1$ THEN 2800

$\therefore 760$ FOR $K 5=J 5+1$ TO M

$2770 \quad J=K .5 \Leftrightarrow F 5=F N F 3$

$278053(11)=53(I 1)+2 * 0(J 5 . K 5) * F 4 * F 5$

2790 NEXT KS NEXT JS

$290053($ I1) $=T * 50 R(52 * 53($ I1)

2810 NEXT TH

2920 I Calculate $r{ }^{*}$

$2830 \quad Y 3=0 \quad$ a $S 1=0 \quad$ a $54=0$

2340 FOR $\mathrm{I}=1$ TO $\mathrm{N}$

$2850 \quad 51=51+Y(I)$ NEXT I $0 \quad Y 7=51 / N$

$296051=0$

$2870 \mathrm{FOR} I=1$ TO $N$ @ $X 3=X(I) @ S 4=S 4+(Y(I)-Y 7){ }^{*} 20$

$S 1=51+(Y(T)+F N F) * 2$

2980 NEXT I

$2890 R_{R}^{2}=1-51 / 54$

3000 PRINT @ PRINT @PRINT " $r " 2=": R 2$

2910 PRINT " $5=": 5$

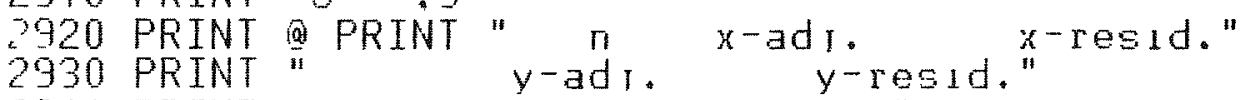

2940 DRTNT"

$y-s t d$. error"

2950 PRINT

$=960$ FOR $I=1$ TO N

2970 PRINT USTNG $2980 ; I, X 1(I), V I(I) @$ PRINT USING 2990 ;

$Y 1(I), V 2(I)$ 6RINT USING $3000: 53(I)$

.980 IMAGE $2 X, D D, 2(2 X, D . D D D E)$

2990 IMAGE $4 X .2(2 X, D . D D D E)$ 


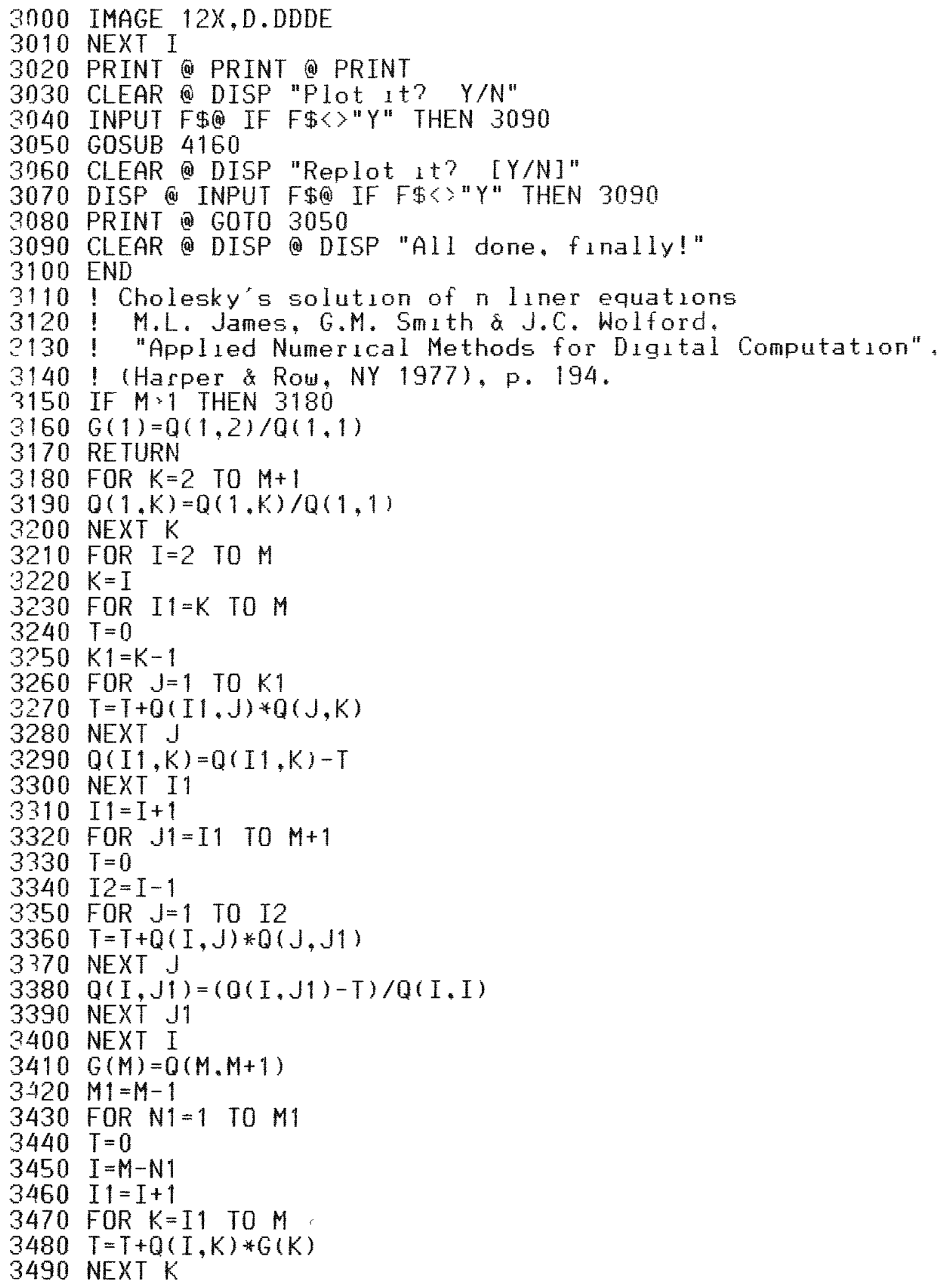




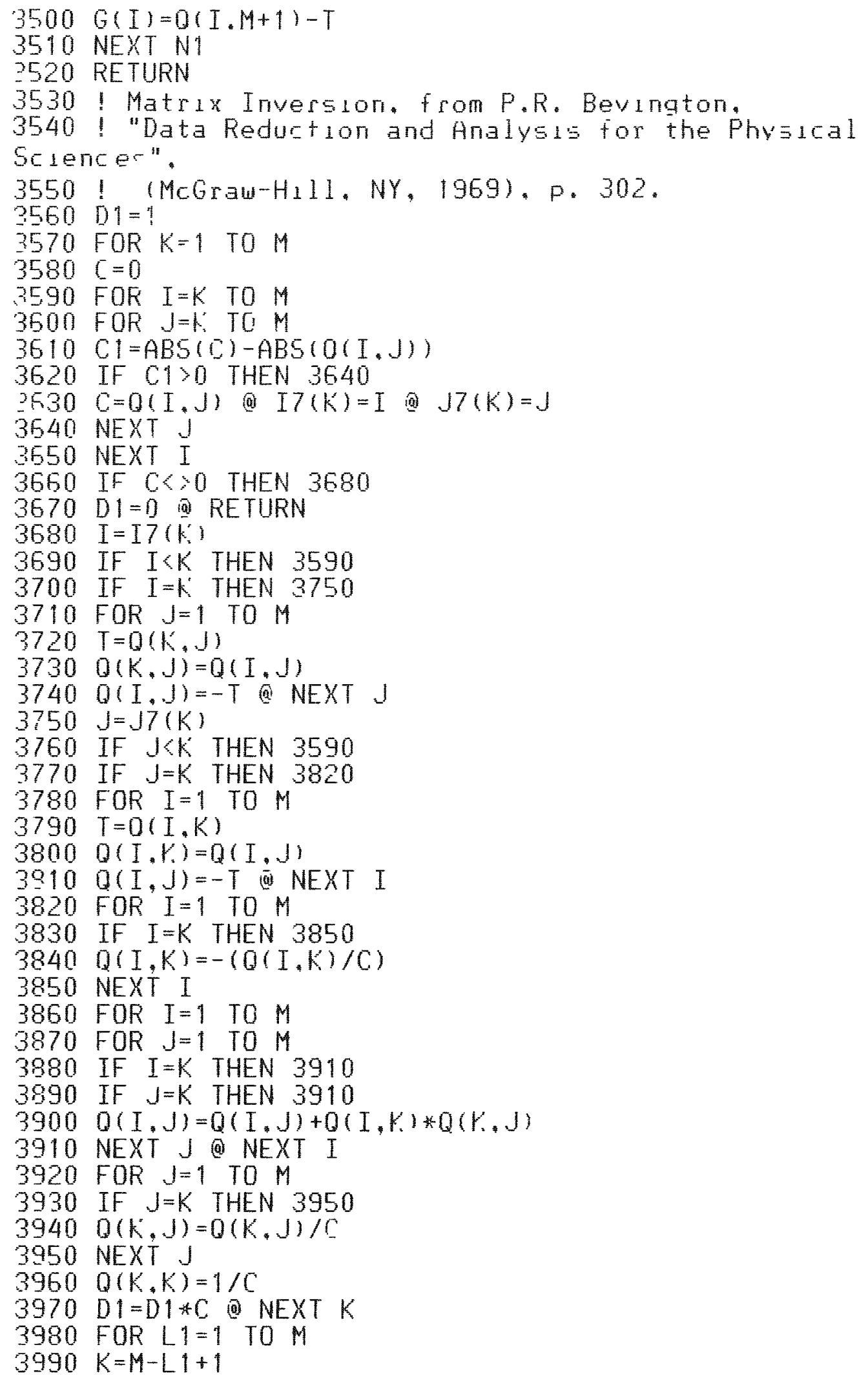




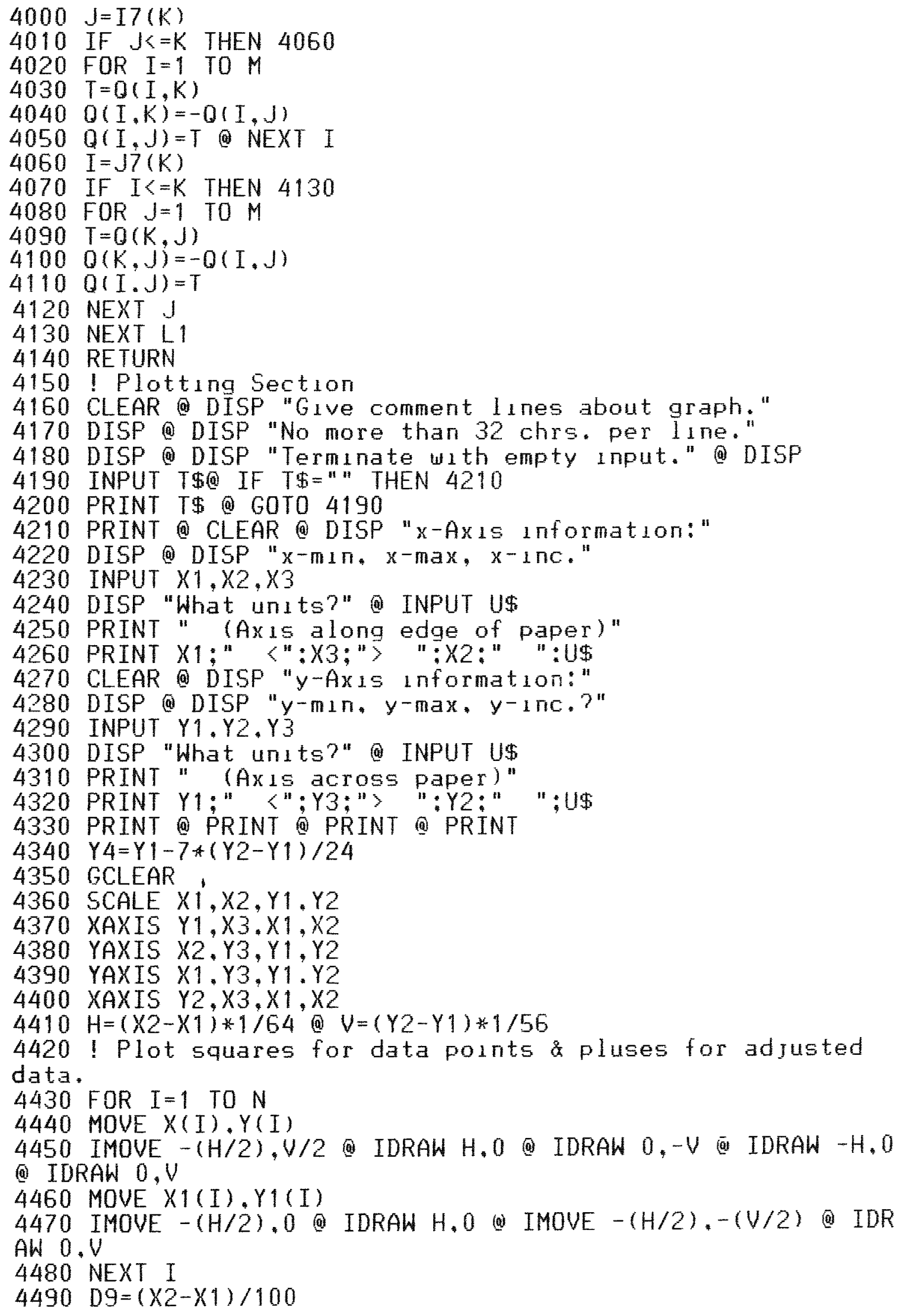




\section{PENUP}

4510 FOR $\times 3=X 1$ TO $\times 2$ STEP D9

$4520 \quad Y 3=0$

4530 IF $X 3=0$ THEN $\times 3=.0001$

4540 PLOT $X 3,-F N F$

4550 NEXT X3

4560 ! Plot $95 \%$ confidence 11 mits

$4570 \mathrm{D} 9=\left(\times 2-X_{1}\right) / 32$ (0) $Z 1=1$ (6) $Y 3=0$

4580 PENUP

$459054=0$ @IF $N=M$ THEN 4840

4600 FOR $I=1$ TO $N$ (0) $X 3=X$ ( I )

$461054=54+(Y(I)+F N F)^{\wedge} 2$ @NEXT I

$4620 \quad 54=\operatorname{SoR}(54 /(N-M))$

$4630 \times 4=\times 1$ @ $\times 5=\times 4+D 9$

4640 ! For higher resolution on confidence limits. change

STEP D9 to STEP D9/5 in the next I ine.

4650 FOR $\times 7=\times 4$ TO $\times 5$ STEP D9

$4660 \times 3=\times 7$

4670 IF $X 3=0$ THEN $\times 3=.0001$

$4680 \quad Z=0$

4690 FOR JIS=1 TO $M$

$4700 \quad J=J 5$ @ $F 4=F N F 3$

$4710 \quad Z=Z+0(J 5, J 5) * F 4 * F 4$

4720 IF $M=1$ THEN 4770

4730 FOR $K 5=J 5+1$ TO $M$

$4740 \quad J=1.5$ (0) $F 5=F N F 3$

$4750 \quad Z=Z+2 * 0(J 5, K 5) * F 4 * F 5$

4760 NEXT K5 NEXT J5

$4770 \quad Z=T * \operatorname{SOR}(Z * S 2)$

4780 PLOT $X 3,-F N F+Z 1 * Z$

4790 NEXT $X 7$

4800 PENUP@ $\times 4=X 4+2 * D 9 @ X 5=X 5+2 * D 9$

4810 IF $X 4<X 2$ THEN 4650

4820 IF $Z 1<0$ THEN 4840

$4830 Z 1=-1$ @ GOTO 4630

4840 COPY@PRINT @PRINT @PRINT@PRINT @PRINT @PRINT @

PRINT @PRINT

4850 RETURN 


\section{REFERENCES}

1. H. 0. Menlove, "Description and Operation Manual for the Active Well Coincidence Counter," Los A1amos Scientific Laboratory report LA-7823-M (May 1979).

2. J. A. Merrill to Merlyn Krick, International Atomic Energy Agency interoffice memorandum DES-130, (August 19, 1982).

3. LASL Group X-6, "MCNP--A General Monte Carlo Code for Neutron and Photon Transport, Version 2B," Los Alamos Scientific Laboratory report LA-7396-M, Rev. (November 1979).

4. W. E. Deming, Statistical Adjustment of Data (John Wiley and Sons, Inc., New York, $1 9 4 3 \longdiv { \text { . } }$

5. J. R. Wolberg, Prediction Analysis (D. Van Nostrand, Inc., Princeton, New Jersey, 1967). 